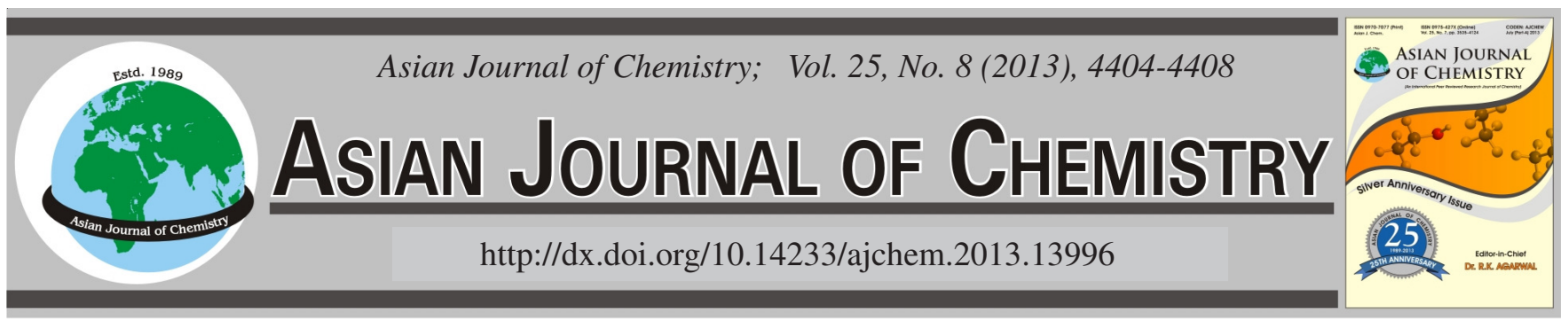

\title{
meso-Tetraphenylporphyriniron(III) Chloride Catalyzed Oxidation of Aniline and Its Substituents by Sodium Perborate: Degradation Kinetics
}

\author{
M. RAJA* and K. KARUNAKARAN
}

Department of Chemistry, Sona College of Technology, Salem- 636 005, India

*Corresponding author: E-mail: raja72slm@yahoo.co.in

\begin{abstract}
Heme-enzymes such as cytochromes P450 have ability to perform extremely difficult oxidations with high selectivity. The kinetic study of oxidation of aniline by sodium perborate with respect to the meso-tetraphenylporphyriniron(III) chloride reveals that there is a slow degradation of the catalyst in this oxidation reaction. The thermodynamic parameters for the oxidation have been determined and discussed. The increase in concentration of $\mathrm{H}^{+}$ions retards the rate of the reaction revealed that the protonated aniline is less reactive in this oxidation reaction. The sodium perborate oxidation with 12 meta- and para-substituted anilines complies with isokinetic relationship and Exner relationship but not to any of the linear free energy relationships. The solvent interaction plays a major role in governing the reactivity. A suitable mechanism and rate law was proposed for this reaction.
\end{abstract}

Key Words: Aniline, Oxidation, Sodium perborate, Meso-tetraphenylporphyriniron(III) chloride.

ᄂ - - - - - - - - - - - - - - - - - - - - - - - - - - - - -

\section{INTRODUCTION}

Chemists have a great deal of attention towards modeling of cytochrome P450 monooxygenase using synthetic metalloporphyrins as they have a strapping resemblance to heme in both structures and catalytic property. The potential of the heme group is to combine with tiny ligands (including molecular oxygen) in enzymatic oxidations. In order to learn, the core of the heme group, the porphyrin ring with the central metal iron atom, has been selected. These complexes can catalyze the oxidation of aniline in simulating the function of cytochrome P450. Literature study ${ }^{1-9}$ has revealed that halogenated metalloporphyrin complexes are excellent catalysts for difficult oxidations with high selectivity. Iron complexes of tetraphenylporphyrins, which has an intermediate structure sandwiched between common natural iron porphyrins with cytochrome P450. To complement the studies in the field of the catalytic oxidation of aniline, the oxidation of aniline by sodium perborate catalyzed by first generation catalyst mesotetraphenylporphyriniron(III) chloride $(5,10,15,20$-tetraphenyl-21h,23h-porphineiron(III) chloride) was taken for the study. Kinetics of oxidation of anilines by variety of oxidants has been reported ${ }^{10-14}$ and only few of them authenticate Hammet equation.

\section{EXPERIMENTAL}

The catalyst meso-tetraphenylporphyriniron(III) chloride (Sigma Aldrich) was used as received. All chemicals and solvents used were of analytical grade (Merck, India). Sodium perborate was used after recrystallization from double distilled water. Aniline was redistilled before use. Acetic acid was purified by redistillation. All the reagents were prepared just before the reactions were carried out. Aqueous solution of sodium perborate was prepared fresh and standardized iodometrically.

Kinetic measurements: Kinetic studies were carried out in $50 \%$ aqueous acetic acid medium by varying the concentration of aniline, sodium perborate, meso-tetraphenylporphyriniron(III) chloride, acetic acid, $\mathrm{H}^{+}$and by varying temperature under pseudo first order conditions with large excess of aniline over sodium perborate. The reaction rate was found by estimating the amount of unconsumed sodium perborate using the modified iodometric method of Kolthoff and $\operatorname{Carr}^{15}$ [suitable aliquots of the reaction mixture was pipette out into $10 \% \mathrm{KI}$ solution $(10 \mathrm{~mL})$ and $10 \%$ of $\mathrm{KNO}_{3}$ solution $(5 \mathrm{~mL})$ and allowed to stand for $0.5 \mathrm{~h}$ in the dark]. The liberated iodine was titrated against standard sodium thiosulphate solution using starch as indicator the reaction was monitored up to $80 \%$ of completion of the reaction. The results obtained were reproducible with an accuracy of $\pm 5 \%$. The rate constants $\left(\mathrm{k}_{\mathrm{obs}}\right)$ were determined by the least square slopes of the linear plots of $\log$ [sodium perborate] and time. The reaction was also carried out using acrylonitrile to find the presence of free radical mechanism. Meta- and para- substituents of aniline were redistilled/recrystallized before use. The oxidation 
reactions of meta- and para-substituents of aniline were studied at different temperatures 293,298, 303,308 and $313 \mathrm{~K}$ to evaluate various thermodynamic parameters.

Stoichiometry and product analysis: A number of experiments by varying the amount of sodium perborate largely in excess over aniline were conducted and the stoichiometry of the reaction was found out. The estimation of unconsumed sodium perborate revealed that one mole of oxidant is consumed by two mole of aniline. The oxidation product was confirmed using TLC. Formation of the azobenzene was also confirmed by UV-visible spectra $\left[\lambda_{\max } 429 \mathrm{~nm}\right]$ of the reaction solutions during and after the completion of the reaction. This was in agreement with the literature value $^{16}$. The $\lambda_{\max }$ of azobenzene was confirmed by comparing with that of the authentic sample in aqueous acetic acid medium.

\section{RESULTS AND DISCUSSION}

Effect of variation of substrate concentration: The increase in aniline concentration increases the reaction rate at constant concentrations of sodium perborate, $\mathrm{H}^{+}$, acetic acid and catalyst. The plot of $\log \mathrm{k}_{\mathrm{obs}}$ versus $\log$ [aniline] was found to be linear (Fig. 1). The slope of the plot is two. It reveals that the order of the reaction with respect to the substrate is two.

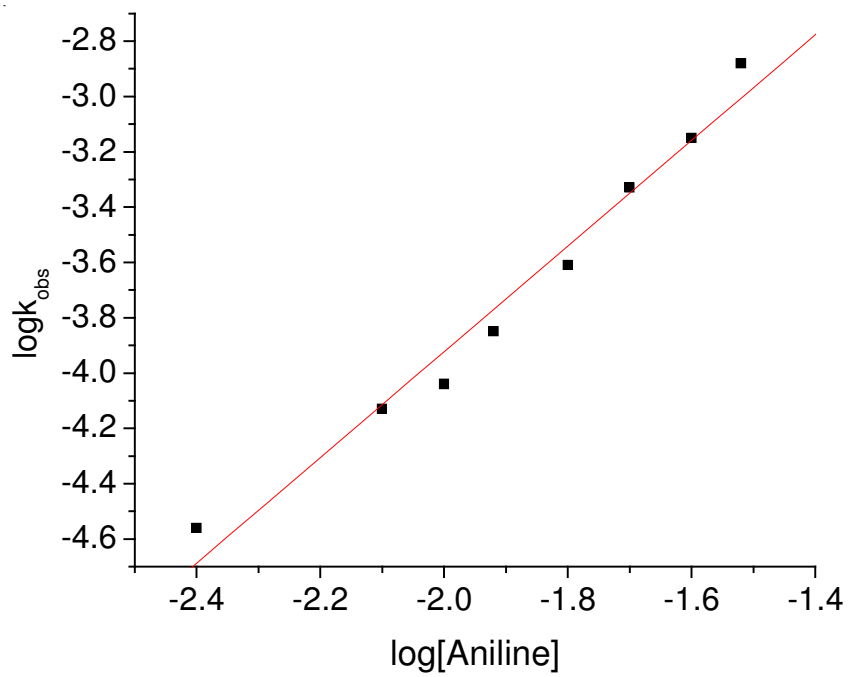

Fig. 1. Plots of $\log \mathrm{k}_{\mathrm{obs}}$ versus $\log$ [aniline] for the oxidation of aniline by sodium perborate catalyzed by meso-tetraphenylporphyriniron(III) chloride [ oxidant] $=0.005 \mathrm{M}$, $[$ catalyst $]=1 \times 10^{-6} \mathrm{M}$, acetic acid: water $=50: 50,\left[\mathrm{H}^{+}\right]=0.2 \mathrm{~N}$, temperature $=303 \mathrm{~K}$

Effect of variation of $\mathbf{H}^{+}$concentration: The increase of hydrogen ion concentration decreases the rate of the reaction. The plot (Fig. 2) $\log \mathrm{k}_{\mathrm{obs}}$ versus $\log \left[\mathrm{H}^{+}\right]$gave a straight line with a negative slope. Aniline in acid medium exists in dual forms, the free bases and conjugate acids ${ }^{17}$ [protonated $\left(\mathrm{C}_{6} \mathrm{H}_{5} \mathrm{NH}_{3}{ }^{+}\right)$and nonprotonated aniline $\left.\left(\mathrm{C}_{6} \mathrm{H}_{5} \mathrm{NH}_{2}\right)\right]$. The literature study ${ }^{18}$ reveals that (increase in $\left[\mathrm{H}^{+}\right]$increases the reaction rate) protonated aniline is more reactive when there is increase in reaction rate with increase of $\left[\mathrm{H}^{+}\right]$. But in the present study increase in $\left[\mathrm{H}^{+}\right]$leads to the increase of protonated aniline which inhibits the reaction rate. This reveals that protonated aniline is a less reactive in this oxidation reaction.

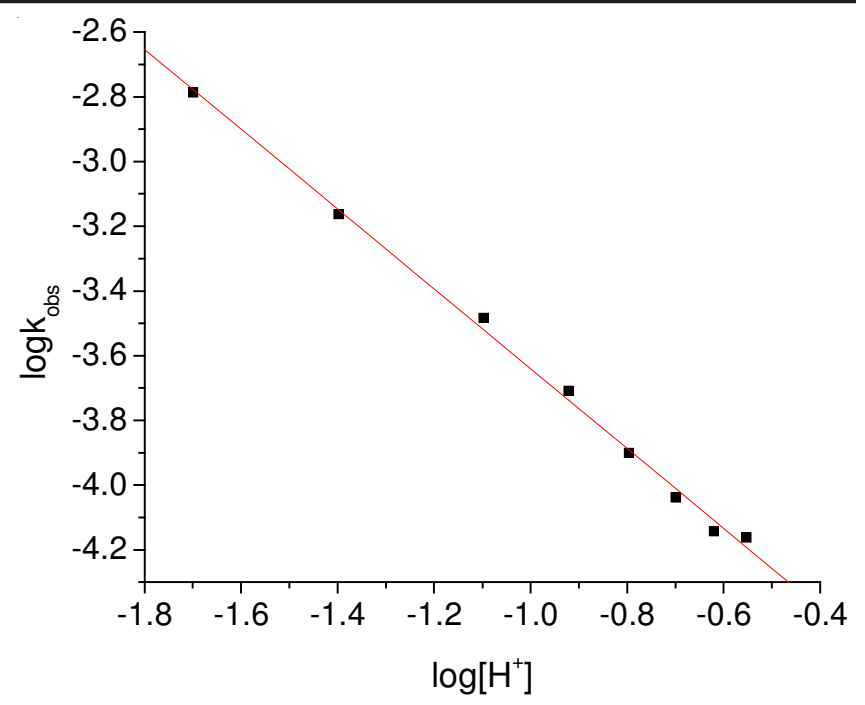

Fig. 2. Plot of $\log \mathrm{k}_{\mathrm{obs}}$ versus $\log \left[\mathrm{H}^{+}\right]$for the oxidation of aniline by sodium perborate catalyzed by meso-tetraphenylporphyriniron(III) chloride. [ substrate $]=0.1 \mathrm{M}$, [oxidant $]=0.005 \mathrm{M}$, [catalyst $]=1 \times 10^{-6} \mathrm{M}$, acetic acid: water $=50: 50$, temperature $=303 \mathrm{~K}$

Effect of variation in catalyst concentration: The oxidation of aniline by sodium perborate in acetic acid is very slow but when catalyzed by meso-tetraphenylporphyriniron (III) chloride the reaction rate increases with a remarkable rate. The increase in the concentration of the catalyst enhances the rate of the reaction. But the plot (Fig. 3) of log $\mathrm{k}_{\mathrm{obs}}$ versus $\log$ [catalyst] was not found to be linear. The curve obtained shows that there is a hindrance in the catalytic activity. The literature study ${ }^{19}$ revealed that the initial ironporphyrin chloride in the oxidation reaction subsequently decayed and a degree of bleaching (degradation of the catalyst) takes place even with a highly halogenated metalloporphyrin. In the present study the variation in catalytic activity may be due to the degradation of the catalyst. The curve obtained on varying the catalyst may be due to the degradation of the meso-tetraphenylporphyriniron(III) chloride (catalyst).

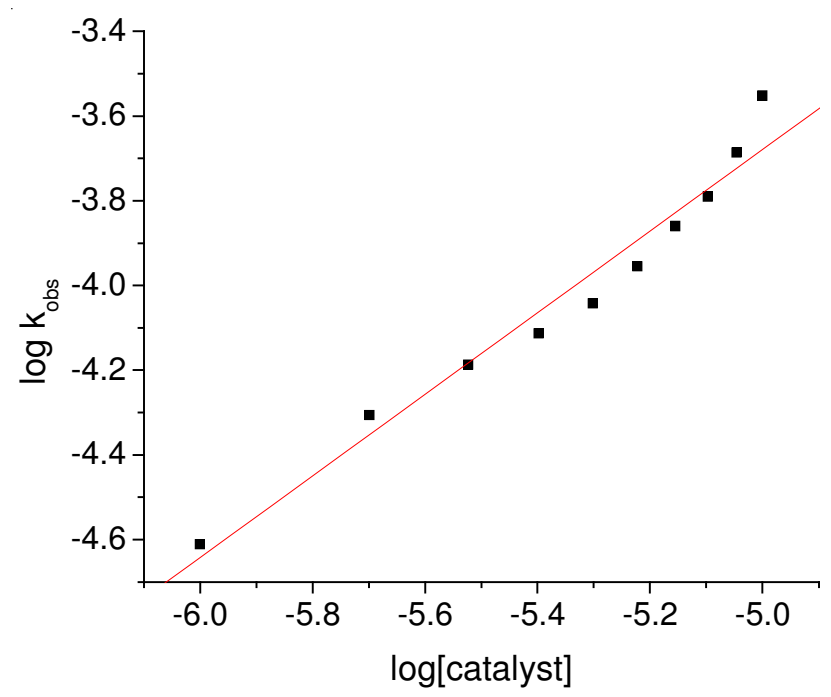

Fig. 3. Plot of $\log \mathrm{k}_{\mathrm{obs}}$ versus $\log$ [meso-tetraphenylporphyriniron(III) chloride] for the oxidation of aniline by sodium perborate catalyzed by meso-tetraphenylporphyriniron(III) chloride. [substrate] $=0.1$ $\mathrm{M}$, [oxidant] $=0.005 \mathrm{M}$, acetic acid:water $=50: 50,\left[\mathrm{H}^{+}\right]=0.2 \mathrm{~N}$, temperature $=303 \mathrm{~K}$ 
Effect of variation in temperature: The oxidation of aniline was studied at different temperatures 297-317 K maintaining the concentration of substrate, oxidant, $\mathrm{H}^{+}$, solvent and catalyst constant. The plot of $\ln \mathrm{k}_{\mathrm{obs}} / \mathrm{T}$ versus $1 / \mathrm{T}$ (Fig. 4) was found to be linear. The thermodynamic parameter $\Delta \mathrm{H}^{\#}$ was found to be $59.49 \mathrm{~kJ} \mathrm{~mol}^{-1}, \Delta \mathrm{S}^{\#}=-125.57 \mathrm{~J} \mathrm{~K}^{-1} \mathrm{~mol}^{-1}, \Delta \mathrm{G}^{\#}=$ $97.41 \mathrm{~kJ} \mathrm{~mol}^{-1}$ and $\mathrm{E}_{\mathrm{a}}=62.00 \mathrm{~kJ} \mathrm{~mol}^{-1} \mathrm{~K}^{-1}$. The negative values of entropy of activation reveals that the intermediate is more firm than the initial state.

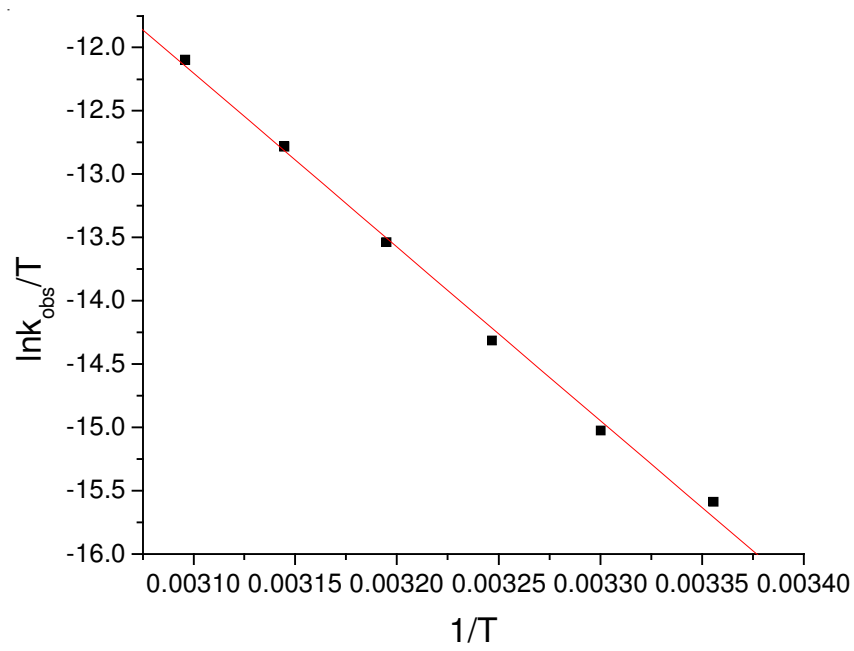

Fig. 4. Plot of $\ln \mathrm{k}_{\mathrm{obs}} / \mathrm{T}$ versus $1 / \mathrm{T}$ for the oxidation of aniline by sodium perborate catalyzed by meso-tetraphenylporphyriniron(III) chloride. [ substrate $]=0.1 \mathrm{M}$, [oxidant $]=0.005 \mathrm{M},[$ catalyst $]=1 \times 10^{-6}$, acetic acid:water $=50: 50,\left[\mathrm{H}^{+}\right]=0.2 \mathrm{~N}$

Effect of dielectric constant: The rate of the reaction was studied by varying aqueous acetic acid mixtures and by maintaining the concentration of aniline, sodium perborate, catalyst and temperature as constant (Table-1). The results obtained shows that the rate increases with decrease in percentage of acetic acid, i.e., with increasing dielectric constant (D) or polarity of the medium. This directs to the conclusion that there is a charge development in the intermediate state suggesting a polar (ionic) mechanism.

\begin{tabular}{|c|c|c|}
\hline \multicolumn{3}{|c|}{$\begin{array}{c}\text { TABLE-1 } \\
\text { PSEUDO-FIRST ORDER RATE CONSTANTS FOR THE } \\
\text { OXIDATION OF ANILINE BY SODIUM PERBORATE } \\
\text { CATALYZED BY MESO-TETRAPHENYLPORPHYRINIRON(III } \\
\text { CHLORIDE IN DIFFERENT ACETIC ACID COMPOSITIONS }\end{array}$} \\
\hline Acetic acid (\%) & $\mathrm{D}$ & $10^{5} \mathrm{k}_{\mathrm{obs}}\left(\mathrm{s}^{-1}\right)$ \\
\hline 70 & 7.54 & 27.90 \\
\hline 60 & 8.13 & 35.14 \\
\hline 50 & 9.05 & 42.37 \\
\hline 40 & 10.32 & 49.60 \\
\hline 30 & 11.46 & 56.83 \\
\hline
\end{tabular}

$[$ Substrate $]=0.1 \mathrm{M}$, oxidant $]=0.005 \mathrm{M},[$ catalyst $]=1 \times 10^{-6} \mathrm{M},\left[\mathrm{H}^{+}\right]$ $=0.2 \mathrm{~N}$, temperature $=303 \mathrm{~K}$.

Substituents effect: The kinetics and oxidation of aniline and $m-\mathrm{Cl}, m-\mathrm{Br}, m-\mathrm{F}, m-\mathrm{CH}_{3}, m-\mathrm{OCH}_{3}, m-\mathrm{NO}_{2}, p-\mathrm{Cl}, p-\mathrm{Br}$, $p-\mathrm{NO}_{2}, p-\mathrm{F}, p-\mathrm{CH}_{3}, p-\mathrm{OCH}_{3}$ anilines in the presence of catalyst were conducted under pseudo-first order conditions at various temperatures to determine various thermodynamic parameters. $\Delta \mathrm{H}^{\#}, \Delta \mathrm{S}^{\#}, \Delta \mathrm{G}^{\#}$ and $\mathrm{E}_{\mathrm{a}}$ were determined and tabulated (Table2). The analysis of the data in the Table- 2 indicates that the oxidation is neither isoenthalphic nor isoentropic but confirms with isokinetic relationship of compensation law. Since the reactions are of ion-polar, it is expected that the entropy of the activated complex for all the anilines should be nearly the same order of magnitude. But due to the variation in polarity of different anilines, $\Delta \mathrm{S}^{\#}$ may be different for different anilines ${ }^{11}$, as observed in the present findings. But the isokinetic relationship exists. The plot of activation enthalpy versus activation entropy follows a straight line as shown in the Fig. 5.

Isokinetic temperature is the temperature at which all the compounds of the series react equally fast ${ }^{11}$ and was determined from the following equation.

$$
\Delta \mathrm{H}^{\#}=\Delta \mathrm{H}^{\mathrm{o}}+\beta \Delta \mathrm{S}^{\#}
$$

where $\beta$ is the isokinetic temperature and it was found to be $326 \mathrm{~K}$ which is lesser than the experimental temperature. The function of isokinetic relationship reveals that a common mechanism is working in all the aniline oxidation reactions.

The values of free energy of activation of the reactions were found to be more or less similar. This is due to the fact

TABLE-2

PSEUDO-FIRST ORDER RATE CONSTANTS FOR MESO-TETRAPHENYLPORPHYRINIRON(III) CHLORIDE CATALYZED SODIUM PERBORATE OXIDATION OF para- AND meta-SUBSTITUTED ANILINES AT DIFFERENT TEMPERATURES, THERMODYNAMIC AND ACTIVATION PARAMETERS

\begin{tabular}{|c|c|c|c|c|c|c|c|c|c|}
\hline \multirow{2}{*}{$\begin{array}{c}\text { Aniline } \\
\text { substituents }\end{array}$} & \multicolumn{5}{|c|}{$10^{5} \mathrm{k}_{\mathrm{obs}}\left(\mathrm{s}^{-1}\right)$} & \multirow{2}{*}{$\begin{array}{c}\Delta \mathrm{H}^{\#} \\
\left(\mathrm{~kJ} \mathrm{~mol}^{-1}\right)\end{array}$} & \multirow{2}{*}{$\begin{array}{c}-\Delta \mathrm{S}^{\#} \\
\left(\mathrm{~J} \mathrm{~K}^{-1} \mathrm{~mol}^{-1}\right)\end{array}$} & \multirow{2}{*}{$\begin{array}{c}\Delta \mathrm{G}^{\#} \\
\left(\mathrm{~kJ} \mathrm{~mol}^{-1}\right)\end{array}$} & \multirow{2}{*}{$\begin{array}{c}\mathrm{E}_{\mathrm{a}} \\
\left(\mathrm{kJ} \mathrm{mol}^{-1} \mathrm{~K}^{-1}\right)\end{array}$} \\
\hline & $293 \mathrm{~K}$ & $298 \mathrm{~K}$ & $303 \mathrm{~K}$ & $308 \mathrm{~K}$ & $313 \mathrm{~K}$ & & & & \\
\hline $\mathrm{H}$ & 5.06 & 9.05 & 18.74 & 41.38 & 89.55 & 59.49 & 125.57 & 97.41 & 62.00 \\
\hline$m-\mathrm{Cl}$ & 4.07 & 8.99 & 17.77 & 35.66 & 75.88 & 56.04 & 137.88 & 97.68 & 58.55 \\
\hline$m-\mathrm{Br}$ & 5.34 & 10.45 & 20.59 & 53.66 & 87.25 & 56.62 & 138.39 & 98.41 & 59.13 \\
\hline$m-\mathrm{F}$ & 3.97 & 8.01 & 16.12 & 34.68 & 70.12 & 55.83 & 139.11 & 97.84 & 58.34 \\
\hline$m-\mathrm{CH}_{3}$ & 3.09 & 6.12 & 12.14 & 26.32 & 54.66 & 55.76 & 141.55 & 98.510 & 58.27 \\
\hline$m-\mathrm{OCH}_{3}$ & 5.58 & 11.08 & 18.31 & 33.52 & 52.01 & 42.69 & 180.42 & 97.17 & 45.20 \\
\hline$m-\mathrm{NO}_{2}$ & 13.154 & 32.21 & 75.41 & 170.21 & 350.77 & 63.13 & 113.3 & 94.33 & 65.64 \\
\hline$p-\mathrm{Cl}$ & 2.11 & 4.44 & 9.02 & 20.1 & 42.18 & 58.17 & 130.38 & 99.35 & 60.68 \\
\hline$p-\mathrm{Br}$ & 4.61 & 9.01 & 18.72 & 38.42 & 78.12 & 55.04 & 140.60 & 97.50 & 57.55 \\
\hline$p-\mathrm{F}$ & 2.58 & 5.22 & 10.43 & 21.09 & 43.56 & 54.53 & 147.05 & 98.94 & 57.04 \\
\hline$p-\mathrm{CH}_{3}$ & 1.89 & 3.45 & 7.65 & 15.30 & 32.76 & 55.66 & 146.15 & 99.80 & 58.17 \\
\hline$p-\mathrm{OCH}_{3}$ & 4.89 & 9.45 & 18.54 & 38.46 & 73.85 & 52.78 & 147.76 & 97.40 & 55.29 \\
\hline$p-\mathrm{NO}_{2}$ & 231.5 & Fast & Fast & Fast & - & - & - & - & - \\
\hline
\end{tabular}

$[$ Substrate $]=0.1 \mathrm{M},[$ oxidant $]=0.005 \mathrm{M}$, $[$ catalyst $]=1 \times 10^{-6} \mathrm{M}$, acetic acid: water $=50: 50\left[\mathrm{H}^{+}\right]=0.2 \mathrm{~N}$. 


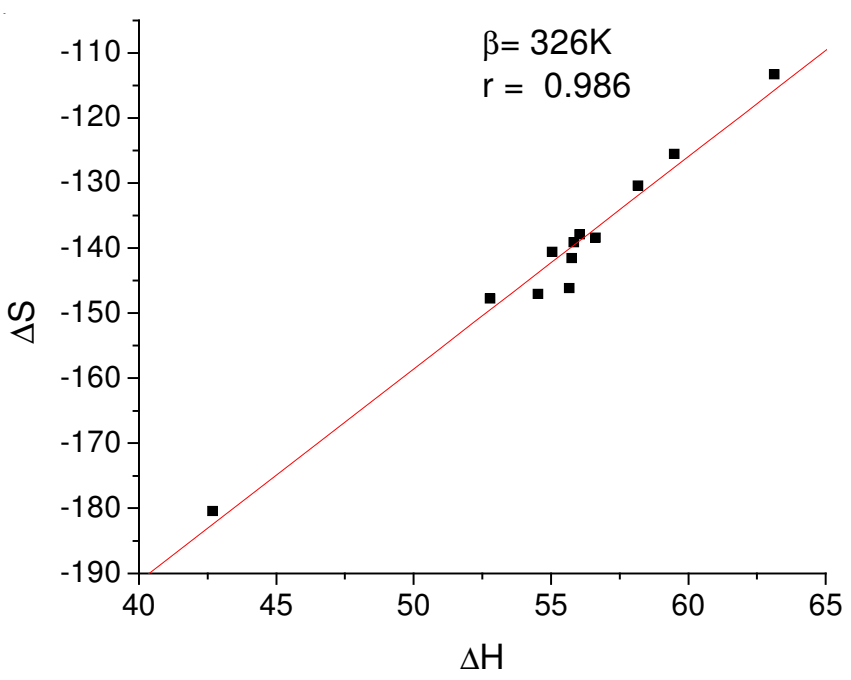

Fig. 5. Isokinetic plot for the meso-tetraphenylporphyriniron(III) chloride catalyzed oxidation of anilines by sodium perborate

that at isokinetic temperature the change of substituent has no influence on the free energy of activation. If the isokinetic temperature is infinite in isoentropic oxidation reactions only the enthalpy of activation finalizes the reactivity and if the isokinetic temperature is zero in isoenthalpic oxidation reactions only the entropy of activation finalizes the reactivity ${ }^{10}$.

However the Exner relationship (Fig. 6), the linear logarithmic relationship between the rates at two temperatures, confirms the operation of a common mechanism throughout the series.

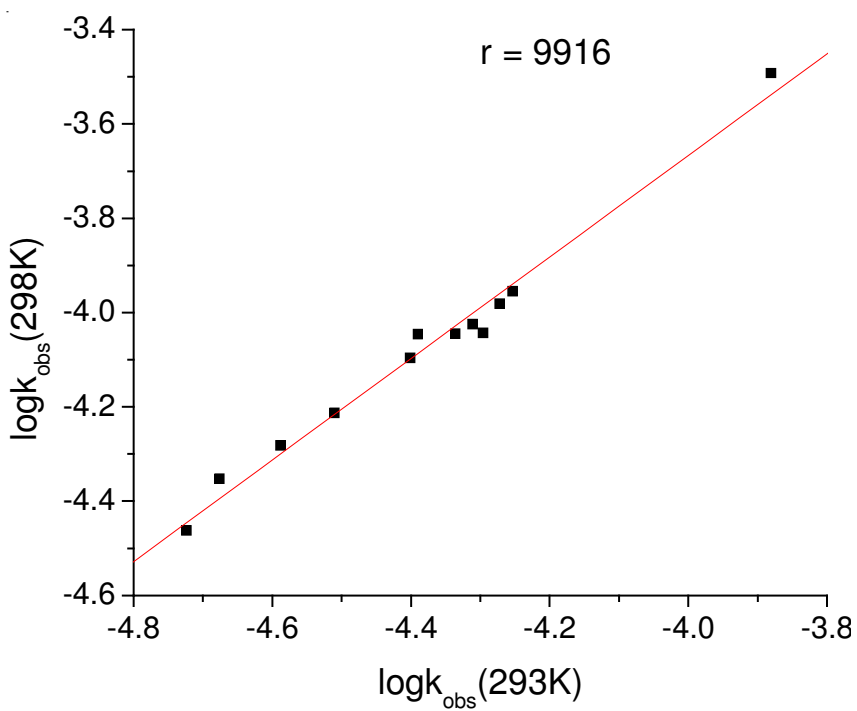

Fig. 6. Exner plot for the meso-tetraphenylporphyriniron(III) chloride catalyzed oxidation of anilines by sodium perborate

Structure-reactivity correlation: The outcome in the Table-2 gives the information that the $\Delta \mathrm{G}^{\#}$ values vary with substrate. This may be due to the dissimilarity in polarity of various anilines. So the obtained rate constants show deviation with substutients. The rate data obtained was also unsuccessful in proving the typical Hammet equation $\log \mathrm{k}_{\mathrm{obs}}$ versus $\sigma$ is a dispersed gram, a sensitive plot (Fig. 7) at the temperatures studied. Literature ${ }^{20}$ reveals that correlation obtained with it were poor as the substituents were conjugated with the reaction

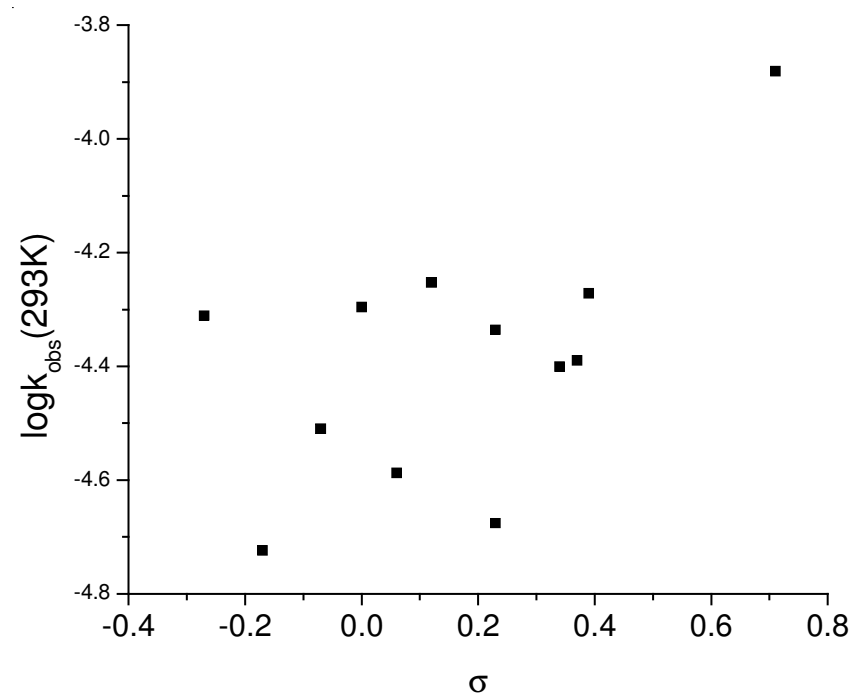

Fig. 7. Hammet plot for the meso-tetraphenylporphyriniron(III) chloride catalyzed oxidation of anilines by sodium perborate

centre, where the problem arose with anilinium ions, where a lone pair of electrons on the $\mathrm{NH}_{2}$ group could be delocalized into substituents such as $p-\mathrm{NO}_{2}$.

The correlation of oxidation rates of meta- and parasubstituted anilines are correlated separately with any of the unit parameters (para: $\sigma,{\sigma_{\mathrm{p}}}^{+}, \sigma_{\mathrm{p}}^{-} ;$meta: $\sigma,{\sigma_{\mathrm{m}}}^{+}$) was also found to be ineffective.

The possible reason for the lack of free energy relationship is that the isokinetic temperature $(326 \mathrm{~K})$ falls beyond the experimental range of temperature. The same possibilities were reported by Buvaneswari and Elango ${ }^{14}$. Operation of inductive and resonance effect opposing each other is known but the present study has no parallel ${ }^{17}$. The less pronounced substituent can be explained only by the compensation effect. Aniline in basic and neutral media is present as free bases but in acid medium exists in dual forms, the free bases and conjugate acids ${ }^{16,17}$. The stoichiometry of the findings shows that two aniline molecules were involved in the reaction. In the literature study ${ }^{21}$ the oxidation also involves two aniline molecules in the rate determining step. This shows that the catalystaniline complex is likely to be the electrophile and free aniline may be the nucleophile. The influence of the substituents on the reactivity of the nucleophile is approximately compensated by the influence of the same substituent on the reactivity of the electrophile ${ }^{12}$. In some of the substituted aniline exact compensation is doubtful and the resultant effect is experienced on the oxidation rate.

Mechanism: The addition of acrylonitrile showed no variation in the reaction rate ruled out the presence of free radical mechanism. So the ionic reaction was preferred in this oxidation study. Generally, the enhancement of the electrophilic activity of peroxide will minimize the importance of undesirable free radical pathways, resulting in a mixture of products $^{22}$. The investigation results illustrate a fascinating note that increase of $\mathrm{H}^{+}$retards the rate of the reaction.

In crystalline state sodium perborate exists as a dimer with anionic formula $\mathrm{B}_{2}\left(\mathrm{O}_{2}\right)_{2}(\mathrm{OH})_{4}{ }^{2-}$. But in aqueous solution it offords $\mathrm{H}_{2} \mathrm{O}_{2}$. Although perboric acid is reported to exist in equilibrium with $\mathrm{H}_{2} \mathrm{O}_{2}$. Based on the stoichiometry of the 
reaction and above experimental results the following reactions (Scheme-I) are believed to constitute the most probable mechanism of the reaction.

$$
\begin{aligned}
& \text { Por Fe }{ }^{\mathrm{III}} \mathrm{Cl}+\mathrm{H}_{2} \mathrm{O}_{2} \stackrel{\mathrm{K}_{1}}{\rightleftharpoons} \quad \mathrm{Por} \mathrm{Fe}^{\mathrm{III}}(\mathrm{O}) \mathrm{Cl}+\mathrm{H}_{2} \mathrm{O} \\
& \mathrm{PhNH}_{2}+\quad \mathrm{Por} \mathrm{Fe}^{\mathrm{III}}(\mathrm{O}) \mathrm{Cl} \stackrel{\mathrm{K}_{2}}{=} \mathrm{PhNH}_{2} \mathrm{Por} \mathrm{Fe}^{\mathrm{III}}(\mathrm{O}) \mathrm{Cl} \\
& \mathrm{PhNH}_{2}+\mathrm{PhNH}_{2} \mathrm{Por} \mathrm{Fe}^{\mathrm{III}}(\mathrm{O}) \mathrm{Cl} \stackrel{\mathrm{k}_{3}}{\longrightarrow} \mathrm{PhN}(\mathrm{O}) \mathrm{H}_{2}+\mathrm{PhNH}_{2} \mathrm{Por} \mathrm{Fe}^{\mathrm{III}} \mathrm{Cl} \quad \text { Slow } \\
& \mathrm{PhN}(\mathrm{O}) \mathrm{H}_{2}+\mathrm{Por} \mathrm{Fe}^{\mathrm{III}}(\mathrm{O}) \mathrm{Cl} \longrightarrow \mathrm{PhNO}+\mathrm{H}_{2} \mathrm{O}+\mathrm{PorFe}^{\mathrm{III}} \mathrm{Cl} \text { Fast } \\
& \mathrm{PhNO}+\mathrm{PhNH}_{2} \longrightarrow \mathrm{PhN}=\mathrm{NPh}+\mathrm{H}_{2} \mathrm{O} \text { Fast }
\end{aligned}
$$

The formation of Por-Fe( $\mathrm{V})=\mathrm{O}$ is in agreement with the literature study ${ }^{23}$ and the intermediate formed was experimentally confirmed at $717 \mathrm{~nm}$. The third step (formation of aniline oxide) was a slow reaction and is likely to be the rate determining step. Based on the above mechanism the rate law can be derived as

$$
\begin{aligned}
& \frac{-\mathrm{d}[\text { oxidizing agent] }}{\mathrm{dt}} \\
& =\mathrm{K}_{1} \mathrm{~K}_{2} \mathrm{k}_{3}\left[\mathrm{PhNH}_{2}\right]^{2}[\mathrm{PorFe}(\mathrm{III}) \mathrm{Cl}][\text { oxidizing agent) }
\end{aligned}
$$

\section{Conclusion}

The oxidation of aniline by meso-tetraphenylporphyriniron(III) chloride is second order with respect to the substrate. The addition of $\mathrm{H}^{+}$retards the rate of the reaction shows that the protonated aniline is less reactive in this oxidation reaction. Kinetic study with respect to catalyst reveals that there is a possibility of degradation of the catalyst. Correlation of the experimental data of solvent reveals that solvent interaction plays a major role in leading the reactivity. The formation of charged intermediate compound was supported by the high negative values of entropy of activation and a most probable mechanism has been proposed for the meso-tetraphenyl-
porphyriniron(III) chloride catalyzed oxidation of anilines by sodium perborate. The validity of isokinetic relationship and thermodynamic relationships have been tested and discussed. With sodium perborate as oxygen donor, the first generation catalyst ironporphyrin, is proved to be a more effective catalyst in oxidizing aniline.

\section{REFERENCES}

1. Y. Iamamoto, M.C.C. Prado, C.H. Sacco, J.K. Ciuffi, D.M. Assis, J.A.P. Maestrin, J.B.A. Melo, O. Baffa and R.O. Nascimento, J. Mol. Catal. A, 117, 259 (1997).

2. S. Tollari, A. Fumagalli and F. Porta, Inorg. Chim. Acta, 247, 71 (1996).

3. S. Campestrini and A. Cagnina, J. Mol. Catal. A, 150, 77 (1999).

4. Q.Z. Lu, R.Q. Yu and G.L. Shen, J. Mol. Catal. A, 198, 9 (2003).

5. C.F. Skrobot, L.V.I. Rosa, A.A.P. Marques, R.P. Martins, J. Rocha, A.A. Valente and Y. Iamamoto, J. Mol. Catal. A, 237, 86 (2005).

6. D. Rutkowska-Zbik and M. Witko, J. Mol. Catal. A, 258, 376 (2006).

7. R.E. Birnbaum, M.R. Le Lacheur, C.A. Horton and W. Tumas, J. Mol. Catal. A, 139, 11 (1999).

8. D. Abatti, M.E.D. Zaniquelli, Y. Iamamoto and Y.M. Idemori, Thin Solid Films, 310, 296 (1997).

9. T.M. Nenoff, M.C. Showalter and K.A. Salaz, J. Mol. Catal. A, 121, 123 (1997).

10. D.S. Bhuvaneshwari and K.P. Elango, Z. Phys. Chem., 220, 697 (2006).

11. S.D. Bhuvaneswari and K.P. Elango, Z. Naturforsch., 60b, 1105 (2005).

12. C. Karunakaran and P.N. Palanysamy, Org. React., 31, 51 (1997).

13. D.S. Bhuvaneshwari and K.P. Elango, J. Indian Chem. Soc., 86, 242 (2009).

14. D.S. Bhuvaneshwari and K.P. Elango, Int. J. Chem. Kinet., 38, 657 (2006).

15. I.M. Kolthoff and E.M. Carr, Anal. Chem., 25, 298 (1953).

16. C. Karunakaran and R. Kamalam, J. Chem. Soc. Perkin Trans. II, 2011 (2002).

17. C. Karunakaran and P.N. Palanysamy, Int. J. Chem. Kinet., 31, 571 (1999).

18. I.H. Um, E.J. Lee and J.S. Min, Tetrahedron, 57, 9585 (2001).

19. P. Prakash and L.J. Franciscamary, J. Serb. Chem. Soc., 70, 1105 (2005).

20. C. Hansch, A. Leo and R.W. Taft, Chem. Rev., 91, 165 (1991).

21. S. Meenakashisundaram, M. Selvaraju, N.M.M. Gowda and K.S. Rangappa, Int. J. Chem. Kinet., 37, 649 (2005).

22. G. Chandramohan, S. Kalyansundharam and R. Renganathan, Int. J. Chem. Kinet., 34, 569 (2002).

23. X.-T. Zhou, H.-B. Ji and Q.-L. Yuan, J. Porphyr. Phthalocya, 12, 94 (2008). 